学術論文

\title{
小児用人工心臓のための超小型磁気浮上モータの改良
}

\section{Improvement of the Compact Maglev Motor for Pediatric Ventricular Assist Device}

\author{
織原＼cjkstart涼雅"1 (学生員)，増澤 徹"1 （正員)，長 真啓*1 (正員)，巽 英介*2
}

Ryoga ORIHARA (Stu. Mem.), Toru MASUZAWA (Mem.), Masahiro OSA (Mem.), Eisuke TATSUMI

\begin{abstract}
A compact maglev motor has been developed for pediatric ventricular assist devices (VADs). The maglev motor consists of a top stator, a bottom stator and a levitated impeller which is suspended with 5-degrees of freedom control. The maglev motor has an outer diameter of $22 \mathrm{~mm}$ and a total length of $33.6 \mathrm{~mm}$. The maglev motor has been improved by magnetic circuit refinement to enhance magnetic suspension characteristics and reduce power consumption. In this study magnetic suspension performance of the improved maglev motor during pumping was evaluated. The developed maglev pediatric VAD indicated sufficient pump performance to regulate a flow rate of $0.5-2.4 \mathrm{~L} / \mathrm{min}$ against a pump head pressure of $100 \mathrm{mmHg}$ at a rotating speed of 4000-5000 rpm. The maximum oscillation amplitudes were successfully suppressed less than $0.05 \mathrm{~mm}$ in axial direction and $0.16 \mathrm{~mm}$ in radial direction. The results indicated that the improvement of the motor significantly contributes to enhance the magnetic suspension and rotation performance.
\end{abstract}

Keywords: maglev motor, 5-degrees of freedom control, ventricular assist device, centrifugal blood pump, pump performance, magnetic suspension performance.

(2018 年 10 月 20 日受付, 2019 年 2 月 7 日再受付, 2019 年 3 月 13 日再々受付)

\section{1 緒言}

心臟移植までの橋渡しや心臟機能の半永久的補助 を目的として，人工心臟が臨床応用されている。近年 では，小児補助循環への期待が高まり，小児用の補助 人工心臓の開発，適用が試みられている[1,2]。本邦で も体外設置型の拍動流式小児用補助人工心臓である EXCOR Pediatricが 2015年6月に承認された。しかし, 拍動流式人工心臟は, ダイヤフラムや逆止弁の使用に よる機械的耐久性の低下, 血液滞留によるポンプ内血 栓の惹起等の課題を持つ。このため, 連続流式の補助 人工心臓の開発が求められる。現在, 最も研究開発が 進んでいる埋め込み型の連続流式小児用人工心臓とし て Jarvik 2015 VAD があげられる。本デバイスでは，ピ ボット軸受でインペラを接触支持することで小型化を 実現するが $[3,4]$, 軸受の耐久性や，摺動部における血 液適合性の課題などの技術的障壁が高く実用化には至 っていない。このことから, 非接触でインペラを支持 できる次世代型の小児用人工心臓の研究開発が望まれ る。

成人用の人工心臟では, 外径が 40 60 mm のラジア ル型の 2 軸（径方向位置）制御磁気浮上モータ，ある

連絡先：増澤 徹, $\overline{\mathrm{T}} 316-8511$ 茨城県日立市中成沢町 4-12-4, 茨城大学工学部機械工学科,

e-mail: toru.masuzawa.5250@vc.ibaraki.ac.jp

*1茨城大学 $*_{2}^{2}$ 国立循環器病研究センター
いはアキシャル型の 3 軸（軸方向位置と傾き角度）制 御磁気浮上モータが用いられている[5, 6]。磁気浮上モ 一タが持つ受動安定性の積極的利用, 受動支持機構の 付加は，デバイス小型化に有効である。しかし，体格 の小さな小児へ埋め込み可能なサイズ（外径 $20 \mathrm{~mm}$ サ イズ）まで磁気浮上モータを超小型化する際には，ス ペースと磁気飽和の観点から, 十分な永久磁石体積や 電磁石コイル巻き数, 磁気吸引力発生に有効な磁路断 面積を確保できず高い支持力と受動剛性が得られない。 また, 永久磁石磁気軸受等の追加的な受動支持機構を 配置する際には, 軸方向または径方向に 5 10 mm 程 度大きくなるため小型化には向かない。このため, 受 動安定性を活用した姿勢安定化によるデバイスの小型 化には限界がある。我々は先行研究の結果から, 外径 $30 \mathrm{~mm}$ 程度までの小径化が小児用人工心臟に求められ る駆動回転数（3500 5500）に対する受動支持の限界 であると考えている[7]。

我々は小児用人工心臟のために，二つのモータのみ で浮上インペラ姿勢の 5 軸を能動制御できる超小型な アキシャル型セルフベアリングモータを開発している。 先行研究で外径 $22 \mathrm{~mm}$, 高さ $33.6 \mathrm{~mm}$ までモータを小 型化, 遠心血液ポンプと組み合わせて, 十分な磁気支 持性能とポンプ性能を実証した[8-10]。一方, 超小型モ 一タゆえに発生支持力とトルクが小さく, ポンプ駆動 とインペラ姿勢安定化のために高消費電力となること 
が課題となった 10$]$ 。これに対し, 理論計算, 有限要素 三次元磁場解析を併用してモータ磁気回路を改良設計 し，モータサイズを変更せずに磁気支持力とトルクを 増加できること, 無負荷状態でインペラを非接触支持 回転した際に消費電力が低減可能なことを実証した [11]。本稿では, 改良した磁気浮上モータを用いて模擬 循環閉回路内でポンプを駆動し, 浮上インペラに対し て流体負荷が働く状態における動特性を評価すること で，モー夕改良の有效性を検証した。

\section{2 方法}

\section{1 超小型磁気浮上モータの概要}

Fig. 1 に小児用人工心臟のための超小型磁気浮上モ ータを示す。本モータは浮上インペラを同一構造の上 部ステータと下部ステータにより，上下から挟み込む ダブルステータ構造をとる。ダブルステータ構造とす ることで小型ながら高トルクを発生可能とする。また, 両ステータで径方向復元力を得られるため, 径方向の 受動剛性を高めることができる。モータステータは 6 つの突極を有し，各突極には集中巻きコイルが巻かれ ている。浮上インペラの両表面には 4 極の永久磁石を 配置している。各モータステータの電磁石により, 4 極 の磁界を発生させ軸方向位置 (Z) と軸方向回りの回転 $\left(\dot{\theta}_{z}\right)$ を制御し, 2 極の磁界を発生させ径方向位置 $(X$, $\mathrm{Y})$ と径方向軸回りの傾き $\left(\theta_{x}, \theta_{y}\right)$ を制御する。各コ イルへ流れる制御電流を調節して, 4 極と 2 極の磁界 を重畳させエアギャップ中に分布させることで, 浮上 インペラの 5 軸と回転を能動的に制御する。

\section{2 磁気浮上モータの 5 軸能動制御原理}

\subsection{1 浮上インペラの軸方向位置及び回転制御原理}

Fig. 2 に軸方向吸引力発生原理を示寸。浮上インペ ラの軸方向位置, 回転制御にはベクトル制御を用いる。 モータステータが発生する 4 極の磁界の d 軸成分を調

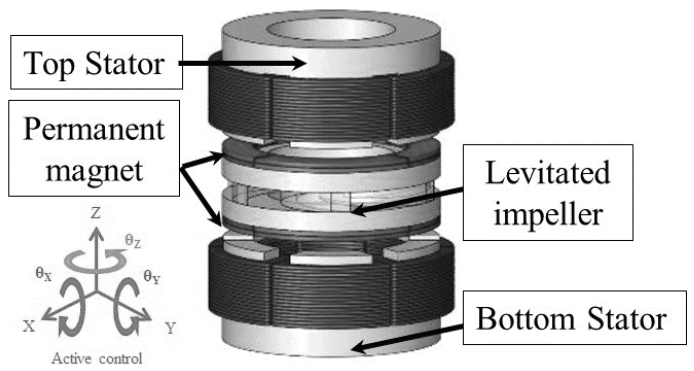

Fig. 1 Structure of 5-DOF control magnetically levitated motor.
節し，永久磁石が発生する磁界に対して，上下のモー 夕の一方では強め磁界，もう一方では弱め磁界とする ことで, 浮上インペラ上下の吸引力に不均衡を生じさ せ，軸方向の位置を制御寸る。また，4極の磁界の $\mathrm{q}$ 軸 成分を調節することで回転トルクを発生させ，浮上イ ンペラの回転数を制御する。

\subsection{2 浮上インペラの径方向位置及び傾き制御原理}

Fig. 3 に径方向位置と径方向軸回りの傾きの独立制 御方法を示す。浮上インペラの径方向位置, 径方向軸 回りの傾き制御には $\mathrm{P} \pm 2$ 極理論を適用する[7]。本研 究では永久磁石が発生する 4 極の磁界に対して，モー タステータで 2 極の磁界を発生させる。上下のモータ ステータが互いに相殺するように傾きトルクを発生さ せると，径方向支持力が重畳される。この径方向支持 力を調節することで, 浮上インペラの径方向位置を制 御する。一方，上下のモータステータがそれぞれ傾き トルクを重畳するように発生させると, 径方向の磁気 支持力は相殺されて傾きトルクのみを生成することが できる。この傾きトルクを調節することで，浮上イン ペラの径方向軸回りの傾きを制御する。

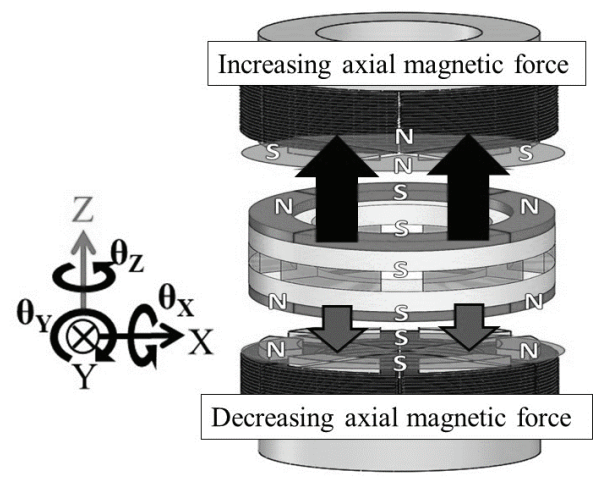

Fig. 2 Principle of axial position control.

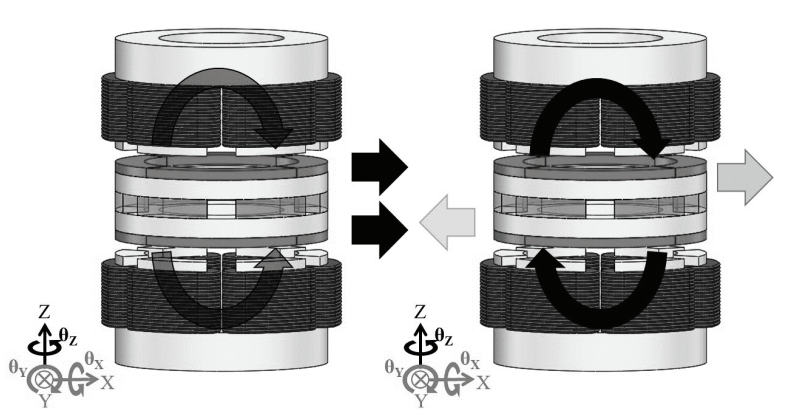

(a) Inclination regulation (b)Radial position regulation

Fig. 3 Inclination angle and radial position control. 


\subsection{3 磁気浮上モータの磁気浮上・回転制御システム}

Fig. 4 に超小型磁気浮上モータの磁気浮上・回転制 御システムの概要を示す。浮上インペラの軸方向位置 $(\mathrm{Z})$, 径方向位置 $(\mathrm{X}, \mathrm{Y})$, 径方向軸回りの傾き角度 $\left(\theta_{x}, \theta_{y}\right)$ は下部ステータの突極内側と浮上インペラ の側面に配置された 5 つの渦電流変位センサ (PU-03A, 株式会社電子応用）により計測される。下部ステータ のスロットに配置された 3 つのホール素子 (HG-302C, 旭化成株式会社）により，永久磁石が発生する磁束を 検出し, 浮上インペラの回転角度を電気角度 $30 \mathrm{deg}$ ご とに計測する。各センサで計測された浮上インペラの 位置および角度をもとに，デジタル PID コントローラ により制御電流值を決定し，パワーアンプを用いて上 下のモータステータの各コイルに印加することで浮上 インペラの 5 軸と回転を能動的に制御する。

\section{3 超小型磁気浮上モータの改良および静特性}

磁気浮上モータのインペラ磁気支持性能向上と消費 電力低減を目指し，理論計算，有限要素三次元磁場解 析を用いて，インペラとステータ間のエアギャップ, 永久磁石厚さ, ステータの突極寸法を再設計し[11], 改 良型モータを製作した。Fig. 5 に製作したモータステ 一タとロータを示す。モータステータコアとロータヨ 一クには電磁軟鉄バルク材 (SUY-1) を使用した。永久 磁石の材料はネオジム磁石 (N-48H) で，保磁力は 960 $\mathrm{kA} / \mathrm{m}$, 残留磁束密度は $1.36 \mathrm{~T}$ である。改良モータでは, 浮上インペラに配置された永久磁石とモータステータ 間のエアギャップを $1.5 \mathrm{~mm}$ から $1.3 \mathrm{~mm}$, 永久磁石厚 さを $1.0 \mathrm{~mm}$ から $0.8 \mathrm{~mm}$ に減少させ，過度な負ばね剛 性の増加を抑えつつ, 磁気回路の磁気抵抗を低減させ

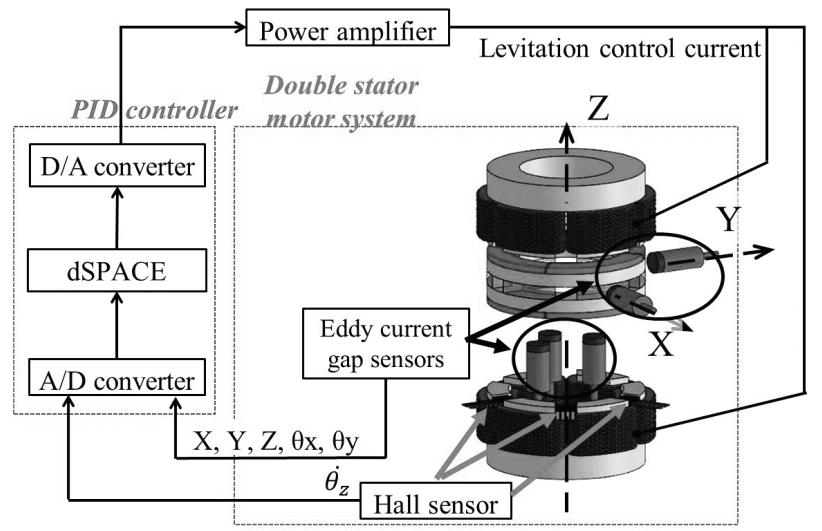

Fig. 4 Block diagram of magnetic suspension and rotation system.
て電磁石励磁により発生する磁気支持力，トルクの増 加を図った。また，ステータ突極内部の磁気飽和を起 こさず，かつコイル巻き数を増加させるようにステー 夕突極一つの断面積を $20.8 \mathrm{~mm}^{2}$ から $17.0 \mathrm{~mm}^{2}$ 一減少 させて，コイル線径は変更せず，コイル巻き数を 66 巻 きから 105 巻きに変更された。コイル巻き数増加に伴 い, 巻線の抵抗が $0.7 \Omega$ から $0.9 \Omega$ 几と約 $29 \%$ 増加し た。先行研究で開発した, 永久磁石厚さ $1.0 \mathrm{~mm}$, エア ギャップ $1.5 \mathrm{~mm}$ のモータを PM1.0AG1.5 モータ，磁 気回路再設計により改良した，永久磁石厚さ $0.8 \mathrm{~mm}$, エアギャップ $1.3 \mathrm{~mm}$ のモータを PM0.8AG1.3 モータ とする。Table 1 に PM1.0AG1.5 モータと PM0.8AG1.3 モータの励磁電流 $1 \mathrm{~A}$ に対する磁気支持力およびトル クの静特性を示す。磁気浮上モータの磁気回路を改良 したことにより，軸方向磁気支持力は $48 \%$, 傾き制御 トルクは $74 \%$ ，回転トルクは $34 \%$ 増加した。巻線抵 抗の増加よりも，支持力とトルク増加による必要電流 值減少の割合が大きいため, 銅損の低減が期待できる。 PM0.8AG1.3 モータで径方向磁気支持力がわずかに低 下したが，本モータは径方向に受動安定性を有してお り，1.1 N/mm の径方向剛性による復元力と径方向剛性 と能動的に発生する磁気支持力を併用することにより 十分インペラを支持できる性能が担保されている。

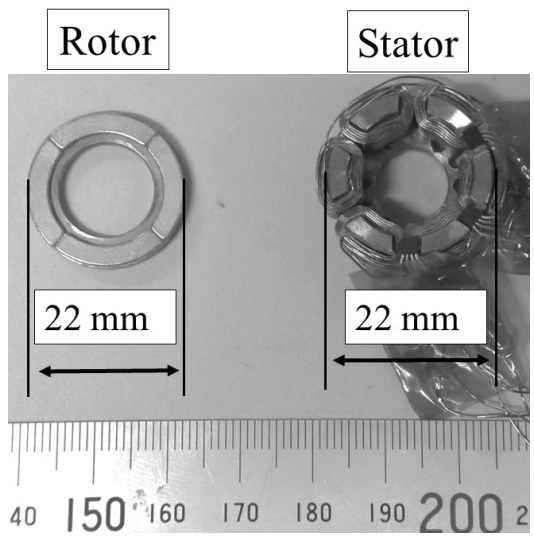

Fig. 5 Rotor and stator for prototype pediatric VAD

Table 1 Magnetic suspension force for improved motor.

\begin{tabular}{|c|c|c|}
\hline & PM1.0AG1.5 & PM0.8AG1.3 \\
\hline Axial & 1.03 & 1.53 \\
suspension force & {$[\mathrm{N} / \mathrm{A}]$} & {$[\mathrm{N} / \mathrm{A}]$} \\
\hline Radial & 0.18 & 0.12 \\
suspension force & {$[\mathrm{N} / \mathrm{A}]$} & {$[\mathrm{N} / \mathrm{A}]$} \\
\hline \multirow{2}{*}{ Inclination torque } & 4.96 & 8.65 \\
& {$[\mathrm{mNm} / \mathrm{A}]$} & {$[\mathrm{mNm} / \mathrm{A}]$} \\
\hline \multirow{2}{*}{ Rotating torque } & 4.35 & 5.84 \\
& {$[\mathrm{mNm} / \mathrm{A}]$} & {$[\mathrm{mNm} / \mathrm{A}]$} \\
\hline
\end{tabular}




\section{4 小肾用補助人工心臓試作機}

Fig. 6 に改良した超小型磁気浮上モータと遠心血液 ポンプを組み合わせた小览用補助人工心臓試作機と浮 上インペラを示す。先行研究で開発した遠心血液ポン プにおいて小児用人工心臓の要求ポンプ性能を十分発 揮可能であったため，本試験機の遠心ポンプには既開 発ポンプと同様の設計寸法を採用した。試作機は幅 42 $\mathrm{mm}$, 高さ $45.3 \mathrm{~mm}$ でポンプの充填量は $3 \mathrm{cc}$ である。 浮上インペラは最外径が $23.6 \mathrm{~mm}$, 高さが $10.9 \mathrm{~mm}$ で ある。製作誤差により，インペラ高さは設計值よりも $0.1 \mathrm{~mm}$ 高くなっている。また, 目玉径は $4 \mathrm{~mm}$, 羽根 高さは $3 \mathrm{~mm}$ で羽根枚数は 6 枚である。インペラにか かる径方向流体力を機構的に抑制するためにダブルボ リュート形状を採用している。浮上インペラとポンプ ケーシング内壁の軸方向, 径方向及び径方向軸回りの 傾き角度の可動域はそれぞれ $0.25 \mathrm{~mm}$ と $0.5 \mathrm{~mm}, 1.25$ deg である。設計值では, 浮上インペラが軸方向の磁 気浮上中心位置で浮上している際の, 浮上インペラに 配置された永久磁石とモータステータ間のエアギャッ プは $1.3 \mathrm{~mm}$ である。

2.5 PM0.8AG1.3 モータを用いた試作機のポンプ駆出性 能とポンプ駆出時の磁気浮上モータの磁気支持性能評 価

Fig. 7 に示寸模擬循環閉回路を用いて試作機のポン プ駆出性能とポンプ駆出時の改良型磁気浮上モータの 磁気支持性能を評価した。模擬循環閉回路は小坚用補 助人工心臓試作機, 血液バッグ，電磁流量計（プロー

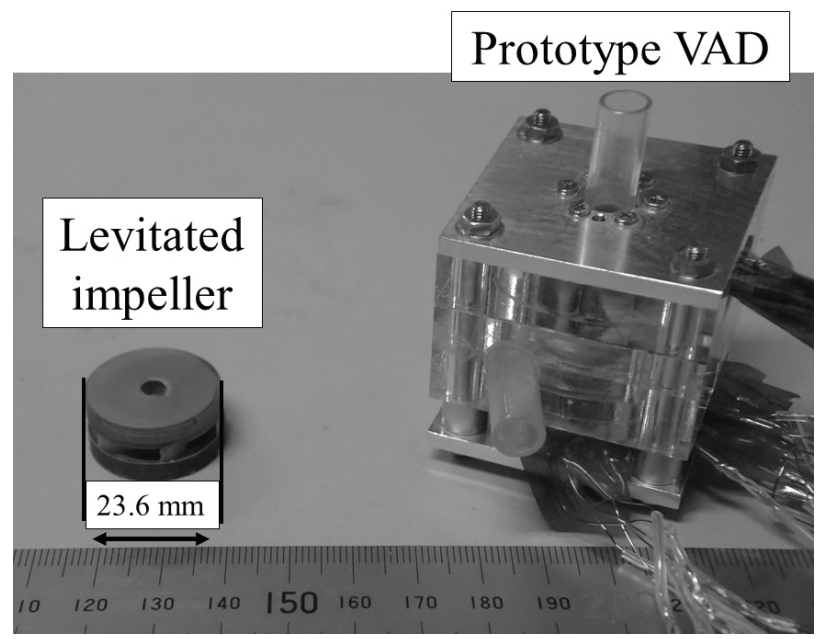

Fig. 6 Levitated impeller and prototype of pediatric VAD.
ブ径 $12 \mathrm{~mm}$ ，日本光電 MFV-2100)，絞り抵抗，ひずみ ゲージ式圧力計 (NECAvio 赤外線テクノロジー株式会 社 9E02-P13）から構成され，回路内には血液の粘性 を模擬した $25^{\circ} \mathrm{C}$ の $40 \mathrm{wt} \%$ グリセリン水溶液を $700 \mathrm{cc}$ で充填している。浮上インペラの製作誤差により，ポ ンプ軸方向の幾何中心と磁気中心が一致していなかっ た。このため，本実験では幾何中心から下部ステータ 側へ $0.12 \mathrm{~mm}$ ずらした位置でインペラを浮上させ，永 久磁石の吸引力が上下で平衡し，消費電力が最も小さ くなるようにした。小児用人工心臓試作機のポンプ流 入口と流出口付近にそれぞれ圧力計を取り付け，二ケ

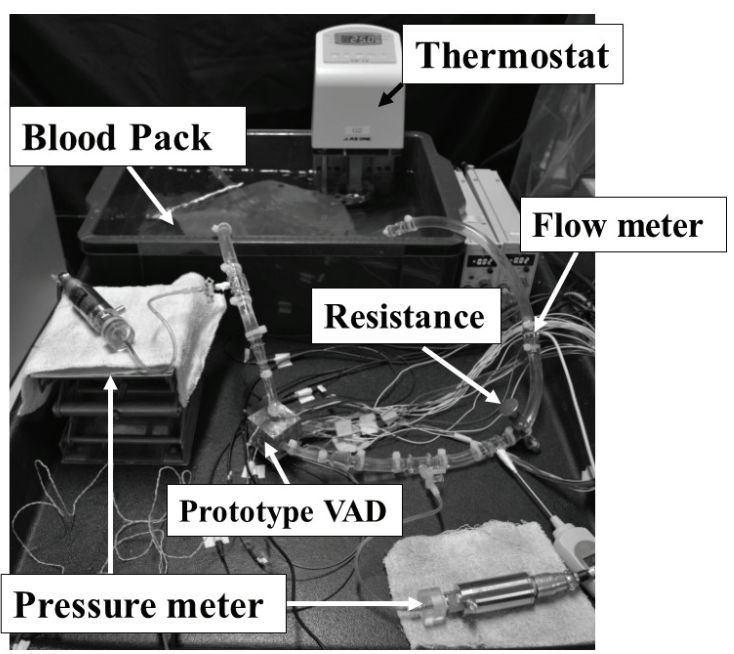

Fig. 7 Closed loop circulation circuit for prototype pump performance evaluation.

Table 2 Digital PID control gains for 5-DOF levitated impeller posture control and rotation control.

\begin{tabular}{|c|c|c|c|}
\hline \multicolumn{4}{|c|}{ PM1.0AG1.5Prototype } \\
\hline & $\mathrm{P}$ & $\mathrm{I}$ & $\mathrm{D}$ \\
\hline Axial & 13 & 0.07 & 0.01 \\
\hline position & {$[\mathrm{A} / \mathrm{mm}]$} & {$[\mathrm{A} / \mathrm{sec} \mathrm{mm}]$} & [A sec $/ \mathrm{mm}]$ \\
\hline Radial & 1.5 & 0 & 0.002 \\
\hline position & {$[\mathrm{A} / \mathrm{mm}]$} & {$[\mathrm{A} / \mathrm{sec} \mathrm{mm}]$} & {$[\mathrm{A} \mathrm{sec} / \mathrm{mm}]$} \\
\hline Inclination & 3.6 & 0.08 & 0.0015 \\
\hline Angle & {$[\mathrm{A} / \mathrm{deg}]$} & {$[\mathrm{A} / \mathrm{sec} \mathrm{deg}]$} & [A sec/deg] \\
\hline Rotation & 0.0005 & 0.0018 & 0 \\
\hline & {$[\mathrm{A} / \mathrm{rpm}]$} & {$[\mathrm{A} / \mathrm{sec} \mathrm{rpm}]$} & [A sec $/ \mathrm{mm}$ ] \\
\hline \multicolumn{4}{|c|}{ PM0.8AG1.3Prototype } \\
\hline & $\mathrm{P}$ & I & $\mathrm{D}$ \\
\hline Axial & 10 & 0.05 & 0.007 \\
\hline position & {$[\mathrm{A} / \mathrm{mm}]$} & {$[\mathrm{A} / \mathrm{sec} \mathrm{mm}]$} & [A sec $/ \mathrm{mm}$ ] \\
\hline Radial & 1.5 & 0 & 0.002 \\
\hline position & {$[\mathrm{A} / \mathrm{mm}]$} & {$[\mathrm{A} / \mathrm{sec} \mathrm{mm}]$} & {$[\mathrm{A} \mathrm{sec} / \mathrm{mm}]$} \\
\hline Inclination & 1.5 & 0.004 & 0.001 \\
\hline Angle & {$[\mathrm{A} / \mathrm{deg}]$} & [A/sec deg] & [A sec/deg] \\
\hline \multirow[t]{2}{*}{ Rotation } & 0.0005 & 0.0018 & 0 \\
\hline & {$[\mathrm{A} / \mathrm{rpm}]$} & {$[\mathrm{A} / \mathrm{sec} \mathrm{rpm}]$} & {$[\mathrm{A} \mathrm{sec} / \mathrm{mm}]$} \\
\hline
\end{tabular}


所の計測圧力の差をポンプ揚程とした。絞り弁により

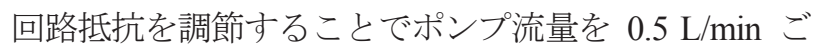
とに変化させた。ポンプ内のインペラを磁気浮上回転 させ, 想定使用回転数範囲である $4000 \mathrm{rpm} ， 4500 \mathrm{rpm}$, $5000 \mathrm{rpm}$ でポンプ特性を測定した。また, ポンプ駆出 時の浮上インペラの軸方向振動振幅, 径方向振動振幅, 径方向軸回りの傾き角度および消費電力を評価した。 先行研究で用いた PM1.0AG1.5 モータと新規に開発し た改良型の PM0.8AG1.3 モータについて，ポンプ駆動 時に用いた磁気浮上制御用 PID コントローラおよび回 転制御用 PI コントローラの制御ゲインを Table 2 に示 す。改良モータの制御ゲインは，ポンプ駆動時の姿勢 安定化に必要な磁気支持剛性を担保しつつ, 制御電流 を可能な限り低減できるように決定した。人工心臓ポ ンプ用の磁気浮上モータでは, 流体力外乱に対して 1 $\mathrm{N} / \mathrm{mm}$ 以上の剛性を有する必要があると考える。ここ で, 磁気浮上モータが発生し得る剛性は磁気支持力の 力係数と P ゲインの積で決定することができる。能動 制御を行う軸方向においては $15.3 \mathrm{~N} / \mathrm{mm}$ となり十分高 い剛性を有する。また, 径方向においては, 受動剛性 と能動的に発生する剛性の併用により $1.28 \mathrm{~N} / \mathrm{mm}$ の剛 性を有し，目標剛性を上回っている。

\section{3 結果・考察}

Fig. 8 に PM0.8AG1.3 モータを用いた人工心臟試作 機の圧流量特性を示す。本ポンプは回転数 4000 5000 $\mathrm{rpm}$ において，ポンプ揚程 $100 \mathrm{mmHg}$ に対して流量を $0.1 \mathrm{~L} / \mathrm{min}$ から $2.2 \mathrm{~L} / \mathrm{min}$ まで調節可能であり, 小览用 補助人工心臟として十分な性能を有した。

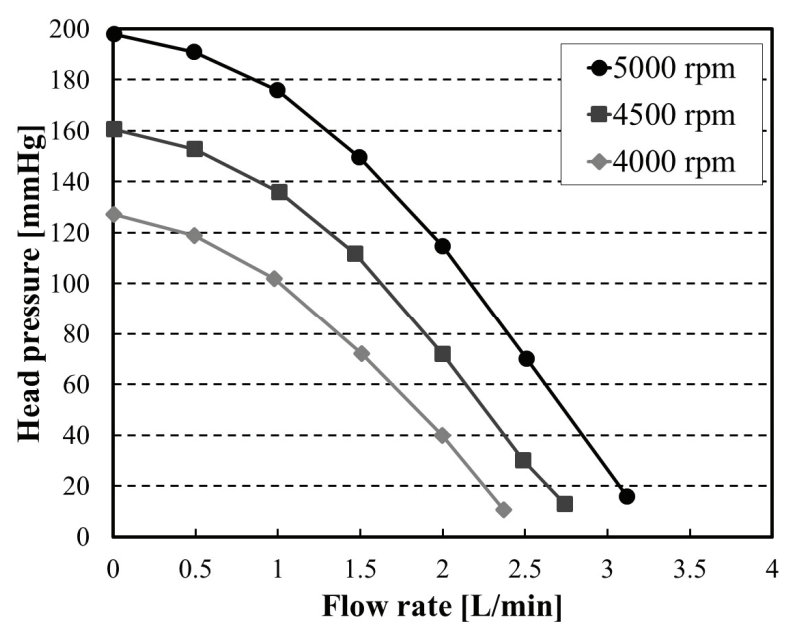

Fig. 8 H-Q characteristics of blood pump.
$-4000 \mathrm{rpm}-4500 \mathrm{rpm}-5000 \mathrm{rpm}$

PM1.0AG1.5 Prototype PM0.8AG1.3 Prototype
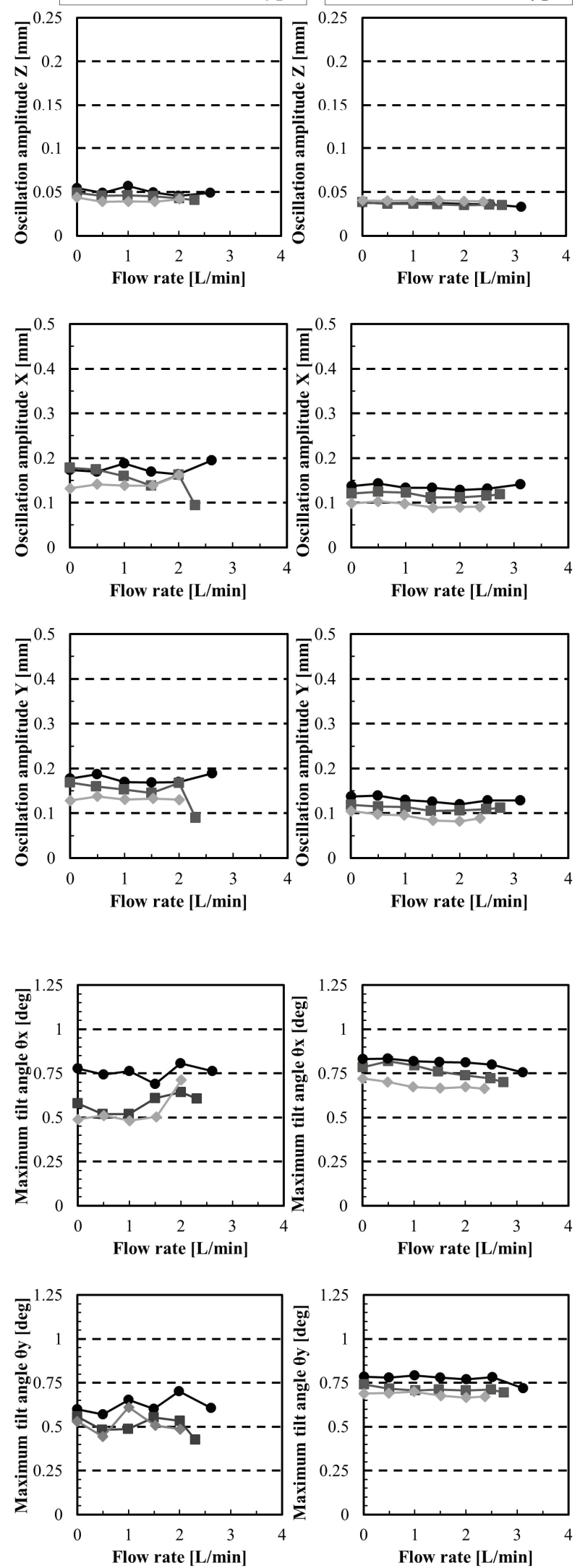

Fig. 9 Oscillation amplitude and maximum tilt angle. 


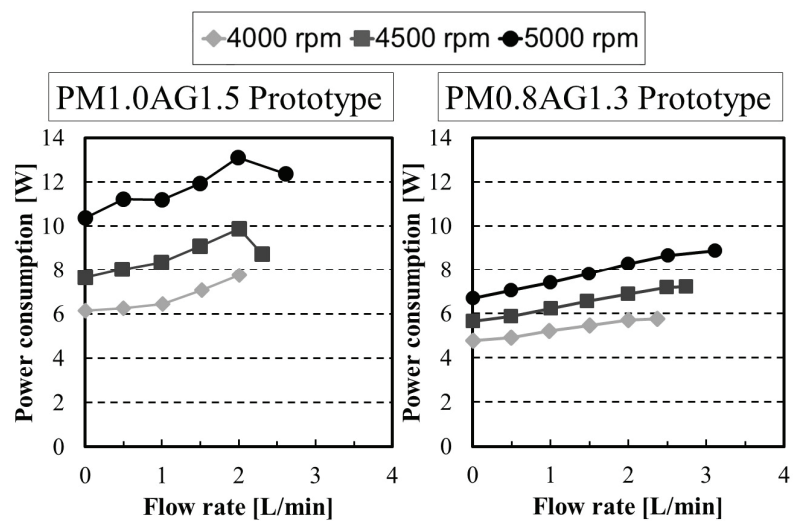

Fig. 10 Power consumption.

Fig. 9 にPM0.8AG1.3 モータの磁気支持性能として， ポンプ駆動時における浮上インペラの軸方向振動振幅, 径方向振動振幅, 径方向軸周りの最大傾き角度を示す。 性能比較のために, 先行研究で評価した PM1.0AG1.5 モータの磁気支持性能の結果を併せて示す。回転数 4000 ５000 rpm において, PM0.8AG1.3 モータの浮上 インペラ軸方向最大振動振幅は $0.046 \mathrm{~mm}$ となった。 また，もっとも支持剛性が低い径方向位置制御に関し ても，受動支持岡性と能動制御を併用することで目標 の支持剛性が得られており, ポンプ駆動時の最大振動 振幅は $0.16 \mathrm{~mm}$ とポンプクリアランスに対して非常に 小さく抑制された。径方向軸周りの傾き角度も $0.87 \mathrm{deg}$ 以下に抑えられ，5 軸すべてにおいて浮上インペラと ポンプケーシングとの接触はなく, 改良モータは血液 適合性を担保するに十分な磁気支持性能を示した。ま た，発生流量と揚程によらず浮上インペラはおおよそ 一定の振動振幅，傾き角度で制振された。本結果は， 小児の成長に応じてポンプ駆動条件を広範囲に変更し ても，本モータが十分に浮上インペラを磁気支持可能 であることを示している。

Fig. 10 にポンプ駆動時における改良前後のモータの 総消費電力を示す。PM0.8AG1.3 モータの消費電力は 全駆動条件において PM1.0AG1.5 モータの消費電力よ りも小さくなった。PM0.8AG1.3 モータの最大消費電 力は 8.9W で, PM1.0AG1.5 モータの最大消費電力 13.1 $\mathrm{W}$ と比較して，4.2 W 低減した。これは，モータ改良 による磁気支持力, トルク増加が制御に必要な電流を 減少させ，銅損低減に有効に働いたためだと考える。 一方，断面積を減少させた突極部で磁束密度が増加す ることで鉄損がわずかに増加にしている可能性がある。 今回の結果では銅損の低減が消費電力低減に優位に働 いたが，今後更なる消費電力低減を図るためには，磁
気コア材料を電磁軟鉄バルク材 (SUY-1) から圧粉磁心 に変更して鉄損の影響を小さくする必要があると考え る。

本稿では模擬循環閉回路内の作動流体に血液の粘 性を模擬した $25^{\circ} \mathrm{C} の 40 \mathrm{wt} \%$ グリセリン水溶液を用い てポンプ駆出時における超小型磁気浮上モータ改良の 有効性を実証した。今後は，浮上インペラの再製作， ステータコアの材料変更を行った後に, 血液を用いて ポンプ駆出性能，インペラ磁気支持性能，消費電力お よび溶血性能等血液適合性の評価を行っていく。

\section{4 結言}

磁気回路再設計により磁気支持力, トルク特性を改 善した超小型 5 軸能動制御磁気浮上モータを用いた小 児用補助人工心臓試作機を開発し，ポンプ駆動時の磁 気浮上回転性能を評価した。想定使用回転数 4000 ５000 rpm において, 改良型磁気浮上モータは浮上イ ンペラの非接触磁気支持を実現し，血液ポンプは小览 の患者（1 歳から 5 歳児）の成長に応じて, 揚程 100 $\mathrm{mmHg}$ に対して流量を $0.1 \mathrm{~L} / \mathrm{min}$ から $2.2 \mathrm{~L} / \mathrm{min}$ まで調 節可能であった。ポンプ駆動時の消費電力を全駆動条 件において低減でき，モータ改良の有効性を示すこと ができた。今後は，インペラ再製作とモータコア材料 の変更による更なる低消費電力化，血液を用いた際の ポンプ性能，ポンプ駆出時のインペラ磁気支持性能, 血液適合性評価を行う。

\section{参考文献}

[1] J. T. Baldwin, H. S. Borovetz, B. W. Duncan, M. J. Gartner, et al., The National Heart, Lung, and Blood Institute Pediatric Circulatory Support, Journal of the American heart association, PP. 147-155, 2006.

[2] 小野 稔, 補助人工心藏の現状と展望, 小児内科, Vol.42, No.5, pp.784-788, 2010.

[3] M. Gibber, Z. J. Wu, W. B. Chang, G. Bianchi, et al., In Vivo Experience of the Child-Size Pediatric Jarvik 2000 Heart: Update. ASAIO Journal, Vol. 56, No. 4, pp. 369-374, 2010.

[4] J. T. Baldwin, I. Adachi, J. Teal, C. A. Almond, et al., Closing in on the PumpKIN Trial of the Jarvik 2015 Ventricular Assist Device, Seminars in Thoracic and Cardiovascular Surgery: Pediatric Cardiac Surgery Annual, Vol. 20, pp. 9-15, 2017.

[5] T. Nisinaka, H. Schima, W. Roethy, A. Rajek, et al, The DuraHeart VAD, a Magnetically Levitated Centirifugal Pump: the University of Vienna bridge-to-transplant experience, Circulation Journal, Vol. 70, pp. 1421-1425, 2006.

[6] K. Bourque, D. B. Gernes, H. M. Loree II, J. S. Richardson, et al., HeartMate III: Pump Design for a Centrifugal LVAD with a 
Magnetically Levitated Rotor, ASAIO Journal, Vol. 47, pp. 401405, 2001.

[7] M. Osa, T. Masuzawa, N. Omori, E. Tatsumi, Radial position active control of double stator axial gap self-bearing motor for pediatric VAD, JSME Journal, Vol. 2, No. 4, pp.1-12, 2015.

[8] 斎藤 拓也, 増澤 徹, 長 真啓, 巽 英介, 小児用人工心 臓用 5 軸制御磁気浮上モータの小型化, 第 23 回「茨城講 演会」講演論文集, pp.29-30， 2015.

[9] M. Osa, T. Masuzawa, T. Saito, E. Tatsumi, Miniaturizing 5DOF fully controlled axial gap maglev motor for pediatric ventricular assist devices, International Journal of AEM, Vol. 52, No. 1-2, pp.191-198, 2016.

[10] 斎藤 拓也, 増澤 徹, 長 真啓, 巽 英介, 超小型磁気浮 上式小児用人工心臓の開発, 日本 AEM 学会誌, Vol. 25, No. 2, pp.130-136, 2017.

[11] 長 真啓, 増澤 徹, 織原 涼雅, 巽 英介, 小児用人工心 臓用 5 軸制御磁気浮上モー夕の高性能化, Dynamics and Design Conference 2018 講演論文集, No. 18-7， 2018. 